\title{
The biodiversity of the United Kingdom's Overseas Territories: a stock take of species occurrence and assessment of key knowledge gaps
}

\author{
Thomas Churchyard $^{1} \cdot$ M. A. Eaton ${ }^{1} \cdot$ S. Havery ${ }^{1}$. \\ J. Hall ${ }^{1} \cdot$ J. Millett ${ }^{1}$ A. Farr ${ }^{2}$ - R. J. Cuthbert ${ }^{1,3}$. \\ C. Stringer ${ }^{1}$ J. A. Vickery ${ }^{1}$
}

Received: 7 August 2015/Revised: 23 May 2016/Accepted: 30 May 2016/

Published online: 11 June 2016

(C) The Author(s) 2016. This article is published with open access at Springerlink.com

\begin{abstract}
Limited financial resources for conservation and growing environmental problems make it vital to base conservation on sound scientific evidence. Small islands hold a disproportionately large amount of the worlds threatened biodiversity but it is among the least well-documented. This paper reports on the most extensive collation and synthesis of biodiversity data to date for the 14 United Kingdom Overseas Territories (UKOTs). A process of literature review and consultation produced 65,259 species records, including 32,216 native species of which 1549 were endemic to a single UKOT. The extent of knowledge of species occurrence varied both between islands and taxonomic groups. It was higher for vertebrates and vascular plants than small bodied invertebrates and nonvascular and for non-Caribbean compared to Caribbean islands, a difference that largely reflects knowledge of invertebrates. Global Red List assessments exist for 2606 species and document 111 of endemic species, $75 \%$ of those assessed, and 291, $12 \%$ of non-endemics, as globally threatened. Using the data to estimate true species richness suggests a further 70,000 native species, including 1800 single island endemics, remain to be documented suggesting the UKOTs as a whole may support over 100,000 native species including 3300 single island endemics.
\end{abstract}

Keywords UK Overseas Territories · Endemic · Biodiversity · IUCN Red List · Islands

Communicated by Simon Ingram.

Electronic supplementary material The online version of this article (doi:10.1007/s10531-016-1149-z) contains supplementary material, which is available to authorized users.

Thomas Churchyard

thomas.churchyard@rspb.org.uk

1 RSPB Centre for Conservation Science, Royal Society for the Protection of Birds, The Lodge, Sandy, Bedfordshire SG19 2DL, UK

2 Buglife-The Invertebrate Conservation Trust, Bug House, Ham Lane, Peterborough PE2 5UU, UK

3 Present Address: Wildlife Conservation Society, Goroka, Eastern Highlands Province,

Papua New Guinea 


\section{Introduction}

Limited financial resources for conservation and growing environmental problems make it vital to base conservation on sound scientific evidence (Sutherland et al. 2004; Segan et al. 2010). Evidence-based decisions help ensure cost-effective management and policies, optimal priority setting and targeted funding (Brooks et al. 2006; Waldron et al. 2013). However, conservation decisions are frequently based on inadequate or biased data and there is a need to improve our knowledge of biodiversity to assist decision-making (Game et al. 2013) and meet obligations under multi lateral agreements such as the Convention of Biological Diversity (CBD).

Small islands hold a disproportionately large amount of the worlds threatened biodiversity and face severe challenges in balancing conservation priorities, environmental protection and economic development (Teelucksingh et al. 2013). Islands hold many range-restricted species and have high levels of endemism compared to mainland areas (Kier et al. 2009). Myers et al. (2000) identified 25 biodiversity hotspots that comprise just $1.4 \%$ of the land surface of the Earth but contain as much as $44 \%$ of all species of vascular plants and $35 \%$ of all species in four vertebrate groups; tropical islands comprise most or all of nine $(36 \%)$ of these hotspots. Furthermore, threat levels are high for many island species due primarily to small range and population sizes (Gaston 1994; Cinotta et al. 2000; Brooks et al. 2002). Despite this combination of importance and threat, island biodiversity is often among some of the least well-documented (Gaston 1994; Kingsford et al. 2009) although there are notable exceptions, more often in temperate and boreal regions.

The small size but high biodiversity value of many islands provides the potential for a high return on investment in species conservation (Tear et al. 2014; Kier et al. 2009). However, their remoteness, restricted resources and small human populations often mean that conservation efforts are severely hampered by a lack of information about species occurrence, distribution and density, which are amongst the most fundamental pieces of biological knowledge required to inform conservation decisions (Kingsford et al. 2009).

This paper reports on biodiversity on the 14 United Kingdom Overseas Territories (UKOTs), which typify this scenario of being rich in biodiversity but poor in resources. Eleven of the UKOTs are relatively remote islands or archipelagos. Gibraltar is linked to the European mainland but, as it is biologically and geologically distinct from it (DurandDelga and Villiaumey 1963; Owen and Rose 1997; Rodriguez-Sanchez et al. 2008), we treat it here as if it were an island. The remaining two territories, the Cyprus Sovereign Base Areas (SBAs) and British Antarctic Territory (BAT), are only small parts of larger landmasses. For the sake of completeness, with respect to the UKOTs as a political entity for which the UK has a responsibility, we include them here.

With the exception of Gibraltar, the human populations on these islands, if present at all, comprise relatively small communities that are highly reliant on the natural environment for their livelihoods, particularly through fisheries and tourism (Foreign Commonwealth Office 2012). They support a wealth of biodiversity (Prince and Croxall 1996; Procter and Fleming 1999; Cuthbert 2004; Angel and Cooper 2006; Sheppard et al. 2013; Churchyard et al. 2014; Friedlander et al. 2014; Weber et al. 2014; Havery et al. 2015) much of which faces immediate threat, particularly from invasive alien species (Hilton and Cuthbert 2010; Dawson et al. 2015). However, conservation action is constrained by the limited, poorly prioritised, and taxonomically biased biodiversity information (Clark and May 2002; Game et al. 2013). The UKOTs' outstanding global importance for biodiversity 
dwarfs that of mainland UK, yet quantitative measures of biodiversity health and qualitative assessments of change are almost entirely lacking (Burns et al. 2013). What information does exist in the UKOTs is fragmented in ownership and accessibility, making it virtually impossible to provide a overarching assessment of the state of biodiversity at the level of individual Territories or the UKOTs as a group. If the UK Government is to meet its commitments under the CBD to stem and halt biodiversity loss on its Overseas Territories it should be a priority to address the many shortcomings in data (Oldfield and Sheppard 1997).

To address this important knowledge gap we undertook the most extensive collation and synthesis of biodiversity data for the UKOTs to date, building on previous assessments (e.g. Procter and Fleming 1999), with the aim of (i) creating a baseline of all species known to occur in the UKOTs, (ii) identifying key knowledge gaps in relation to (a) individual UKOTs, (b) taxonomic groups (c) assessments against IUCN Red List criteria, (iii) estimating what the true species richness of the UKOTs might be, and (iv) investigating what factors determine our knowledge of biodiversity at the UKOT level.

\section{Materials and methods}

The UKOTs consist of Anguilla, Bermuda, British Antarctic Territory (BAT), British Indian Ocean Territory (BIOT), British Virgin Islands (BVI), Cayman Islands, Cyprus Sovereign Base Areas (SBAs), Falkland Islands, Gibraltar, Montserrat, Pitcairn Islands, St Helena, Ascension and Tristan da Cunha, South Georgia and the South Sandwich Islands (SGSSI) and Turks and Caicos Islands (TCI) (Fig. 1). Eleven of the UKOTs are islands and archipelagos, the three exceptions being BAT, Cyprus SBAs and Gibraltar. BAT comprises a segment of the Antarctic continent as agreed under the Antarctic Treaty. Cyprus SBAs

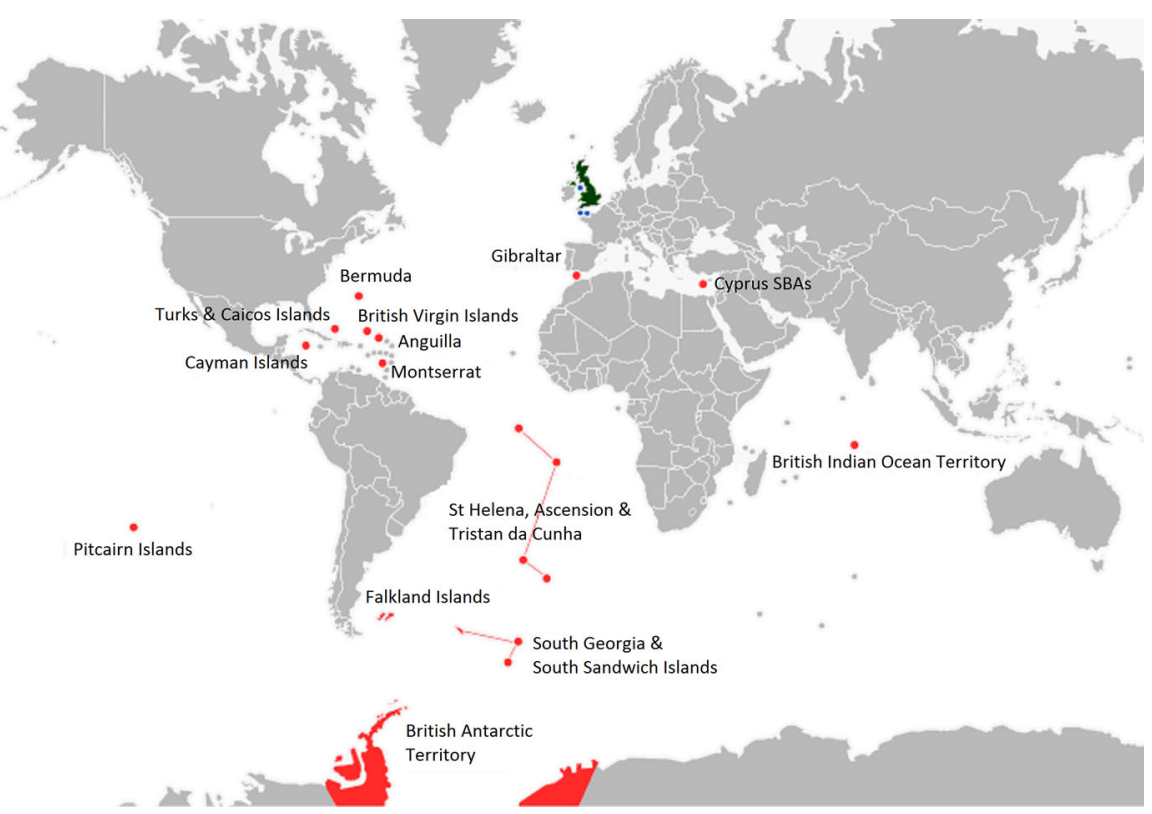

Fig. 1 Map showing the locations of the UK Overseas Territories (UKOTs) 
comprises two geographically separate areas covering a total area of $254 \mathrm{~km}^{2}$ which equates to ca $3 \%$ of the land area of Cyprus (SBAA 2015). Gibraltar is attached to mainland Europe with Spain forming the northern border, although we treat Gibraltar here as an island (see above). Three of the UKOTs, St Helena, Ascension and Tristan da Cunha, are administered as a single UKOT by the British government but biogeographically they are very distinct and thus we treat them separately here. Therefore, we consider the 14 UKOTs as 16 separate entities, and refer to all 16 as UKOTs hereafter.

\section{Creating a baseline}

We created species lists for each UKOT, covering all taxonomic groups, following a four-step approach. First, species lists for each UKOT were created through a systematic review of peer reviewed literature from Web of Science (isiknowledge.com), Google Scholar (scholar.google.co.uk) and the Biodiversity Heritage Library. Searches for each UKOT were standardised by searching first by the UKOT name, then filtering for all biological research areas and then by pairing each UKOT name with that of a taxonomic group (e.g. 'Pitcairn + Mollusca'). Secondly, we corresponded with UKOT Government departments and both UKOTand UK-based non-governmental organisations (NGOs), universities and museums to identify relevant experts who could identify and provide data from further sources (e.g. unpublished reports and datasets). This process highlighted areas where data were missing and informed a third stage, in which draft species lists were circulated within professional networks of experts, many not consulted previously, for submission of additional literature and data. The fourth and final step was to check the taxonomy, particularly to correct species records that were synonymous. The completed species lists were assessed by individual experts for key taxonomic groups and/or against respected on-line databases (such as World Register of Marine Species, www.marinespecies.org). The exception to the process was for BAT, for which we used a species list provided by the British Antarctic Survey, derived from a recent atlas of all current species records for the Southern ocean (De Broyer et al. 2014).

We collected records at the level of species and UKOT. For the marine environment, where possible, data was recorded from territorial waters, which extends to 12 nautical miles (nm) for the island UKOTs and $3 \mathrm{~nm}$ for Gibraltar and Cyprus SBAs. In accordance with the Antarctic Treaty, BAT has no territorial waters. We use a cut-off of six nm from the maximum ice-shelf cover to incorporate all biodiversity from around BAT based on British Antarctic Survey data. Each species record comprised, at a minimum, a location (from UKOT down to island level), IUCN Red List category and type of record (survey count, ad hoc count, incidental report). For species for which we collated multiple records (e.g. repeated counts, or records from multiple locations in a Territory) each data point was recorded separately.

For some taxonomic groups, most notably birds and mammals, records for individual UKOTs will have included migrant species, many occurring only infrequently. For some UKOTs it was not possible to determine which species were regularly occurring and/or breeding, and which were migrants, so our database includes all records without distinction.

\section{Identifying knowledge gaps}

In order to identify the key knowledge gaps across both UKOTs and taxonomic groups, we classified the level of knowledge of species occurrence for each taxonomic group within each UKOT. The taxonomic rank at which we defined groups varied; for taxa for which data were relatively sparse, we summarised results at a higher rank including kingdom 
(fungi) but more often phylum (e.g. Bryozoa, Cnidaria) or groups of phyla (worms, which included phyla such as Nematoda, Nematomorpha and Annelida), whereas for the betterstudied groups we summarised data at the rank of class (e.g. mammals, amphibians). We looked at coverage of IUCN Red List assessments by taxon, UKOT and endemism. The state of knowledge for the occurrence of each taxonomic group in a UKOT was scored as follows: $4=$ list compiled from authoritative literature, confident of complete or near complete coverage of taxonomic classes, input from experts received, $3=$ list compiled from authoritative literature, coverage of taxonomic classes reasonable but known to be incomplete, little or no input from experts, 2 = preliminary list known to be incomplete, no input from experts, $1=$ no records found. We calculated median scores for both taxonomic groups (across all UKOTs) and UKOTs (across all taxonomic groups) to reveal variation in knowledge.

\section{Estimating true species richness}

For a small number of taxonomic groups (birds, mammals, amphibians, reptiles and vascular plants) we considered species lists for each UKOT to be complete (with the exception of Cyprus SBAs), and for two UKOTs (Bermuda and South Georgia and the Sandwich Islands) we considered lists to be entire across nearly all taxonomic groups. For other UKOTs and taxonomic group combinations a more limited number of lists were considered complete e.g. Lichens on Ascension, Arachnids on Pitcairn. Note that, as stated above, the taxonomic rank at which these groups were defined varied. We used the differences in species richness between UKOTs, and between taxonomic groups, (based on complete UKOT/taxonomic groups only) to attempt to estimate the total number of species likely to be present in all UKOTs, whether documented or not. This relied on the assumption that the between-UKOT pattern of differences was the same for taxonomic groups that were not well-covered as it was for those with complete lists (e.g. the UKOTs that were known to be relatively species rich for some taxonomic groups were also species rich for other groups), and likewise, the between-taxonomic group differences were the same for UKOTs with and without complete lists (e.g. the taxonomic groups known to be relatively species rich in some UKOTs were also species rich in the other UKOTs). We fitted a Generalised Linear Model, assuming a Poisson error distribution and with correction for over dispersion, with UKOT and taxonomic group fitted as fixed effects, to all UKOT-taxonomic group estimates believed to be complete (of which there were 130 out of the 378 UKOT-taxonomic group combinations). The parameter estimates (for UKOT and taxonomic groups) from this model were used to estimate species numbers (and $95 \%$ confidence limits) for all the UKOT-taxonomic group combinations which were believed to be incomplete $(n=248)$. These estimates were summed and added to the totals of species in taxonomic groups with complete coverage to give an estimate for species richness in each UKOT. Summing species totals for each UKOT overestimates the number of species across the UKOT suite as many species occur on multiple UKOTs. We assumed the extent of this was the same across recorded and unrecorded species, and hence adjusted the summed estimate of the latter accordingly in order to derive an estimate of species richness across the entire UKOT suite. This process was repeated using the same complete UKOTs-taxonomic group estimates for endemic groups, with the omission of the final scaling process as there is no overlap between UKOTs for endemic species. However, due to the lack of knowledge on endemics for seven taxonomic groups (brachiopods, tunicates, tardigrades, echinoderms, bryozoans, lower plants and smaller groups of invertebrates lumped as 'other' groups) 
these taxa were excluded from the analysis of endemic numbers. Analyses were conducted using SAS version 9.3 (SAS Institute 2011).

\section{Identifying factors that influence knowledge of biodiversity}

We investigated the extent to which the level of knowledge within individual UKOTs could be explained by variables describing geography (Territory area, latitude, longitude, distance from London and nearest continental landmass, and geographical region as described using six ocean/sea areas), economy (GDP and GDP per capita), local biological recording capacity (presence of specialist recorder, research station, human population, visitor numbers) and history of human occupation (date since European discovery, settlement, and UK annexation) by modelling the relationship between these variables and a measure of the knowledge of biodiversity in each territory, defined as the number of taxonomic groups in each territory for which knowledge was scored as 4 (near-complete or complete coverage). Predictors, which included continuous, categorical and binomial variables, are described further in the Supplementary Online Material (Online Resource 1). We looked for relationships using generalized linear modelling (GLM). Firstly, we tested for co-linearity by creating a global model and calculating variance inflation factors (VIF) for all variables (following Blanchet et al. 2008). For those variables with VIF above 5, indicating a high degree of co-linearity, we used pair-wise comparisons to identify highly correlated pairs, and of these removed the variable with the weakest univariate relationship with our response variable. We then recalculated VIF for all (11) remaining variables to check for any substantial remaining co-linearity.

To look for significant uni-variate relationships, we generated a series of single-predictor Poisson GLMs, using a log-link function, (using Bonferroni correction for multiple testing). We then created multivariate GLMs including no more than two of the remaining predictor variables (not more due to the small sample size of UKOTs) and using combinations of the variables restricted to a single variable from each of the variable classes. To maintain model simplicity given the small sample size we did not consider interactions between predictive variables. Models were compared using Akaike's information criterion (AIC) adjusted for small sample sizes (Burnham and Anderson 2007), and the performance of the model with the lowest AIC assessed against the null model using a likelihood ratio test.

\section{Results}

\section{A stocktake of biodiversity_creating a baseline}

We collated data from 647 papers, reports and catalogues and through consultation with over 20 NGOs, 17 government departments and linked organisations, direct contact with 122 relevant experts and indirect contact (i.e. via people with which we had direct contact) with more than 250 additional individuals.

This process of review and consultation resulted in 65,259 records of 32,216 species native to the UKOTs (Fig. 2). For many species we collated multiple records from a single UKOT; the total of unique species-UKOT combinations was 41,609. In addition, we identified 2012 species non-native to the UKOT on which they were recorded. 
The highest number of native species were documented on Bermuda (9049), nearly three times greater than any other UKOT, followed by British Virgin Islands (3315), Cayman Islands (3192) and South Georgia and the South Sandwich Islands (3183). Of the 32,216 native species documented, 1549 species were endemic to a single UKOT with particularly high numbers of endemic insects (519), vascular plants (182), arachnids (149) and crustaceans (127), but also 74 endemic species of vertebrate. Although all UKOTs (except the Cyprus SBAs) held endemic UKOT species, the level of endemism (number of species documented) varied markedly from over 500 on St Helena (over $80 \%$ of which were terrestrial invertebrates) to less than 10 for Gibraltar, BAT and BIOT (Fig. 2). Matrices of known species richness by taxonomic group and UKOT are given in the Supplementary Online Material for all species (Online Resource 2), and for endemics (Online Resource 3).

\section{Identifying gaps in knowledge for taxonomic groups and UKOTs}

The extent of knowledge of species occurrence varied both between taxonomic groups (Kruskal-Wallis chi $\mathrm{sq}=208.52$, $\mathrm{df}=24, \mathrm{p}$ value $\leq 0.001$ ) and between UKOTs (Kruskal-Wallis chi $\mathrm{sq}=79.02, \mathrm{df}=15, \mathrm{p}$ value $\leq 0.001$ ): it was higher for vertebrates than for small bodied invertebrates (such as tardigrades and bryozoans) (Fig. 3) and generally low for non-vascular plants, worms, brachiopods and tardigrades across most

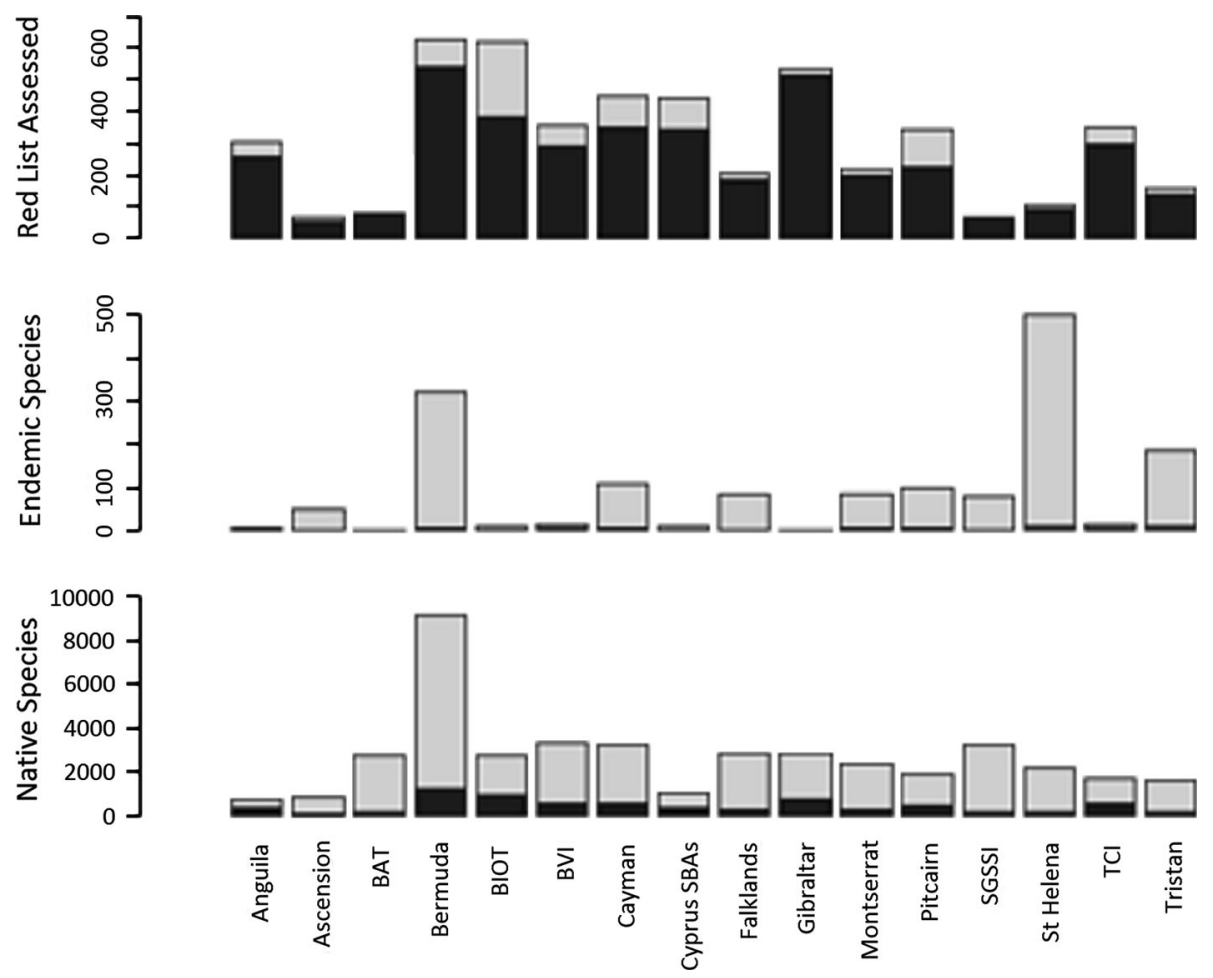

Fig. 2 Number of native species, endemic species and Red List assessed species in each UKOT. Darker shading represents number of vertebrates 
(a)

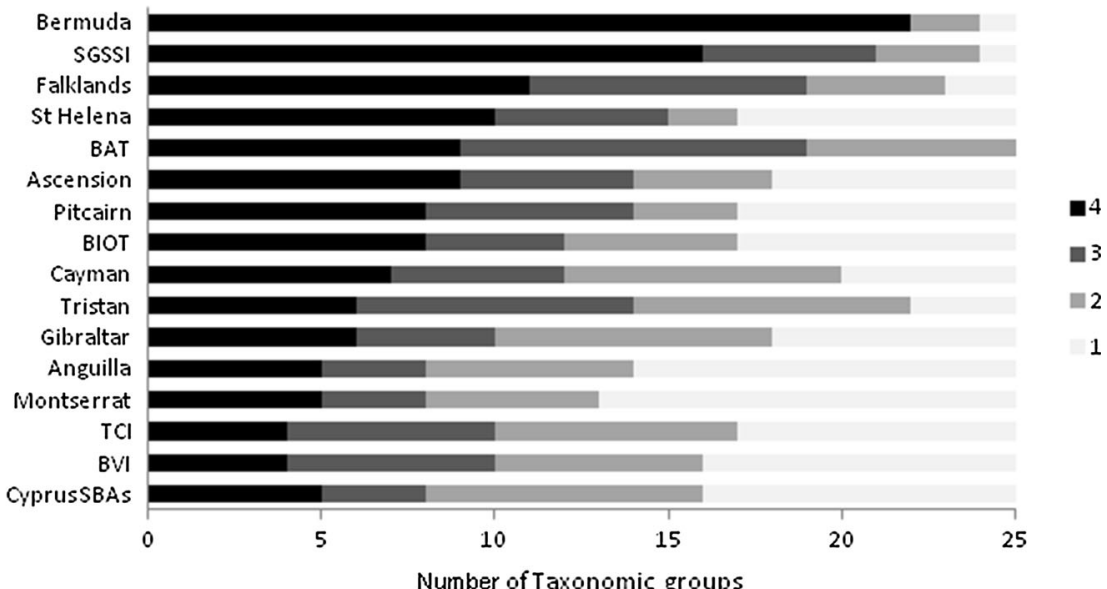

(b)

Number of Taxonomic groups

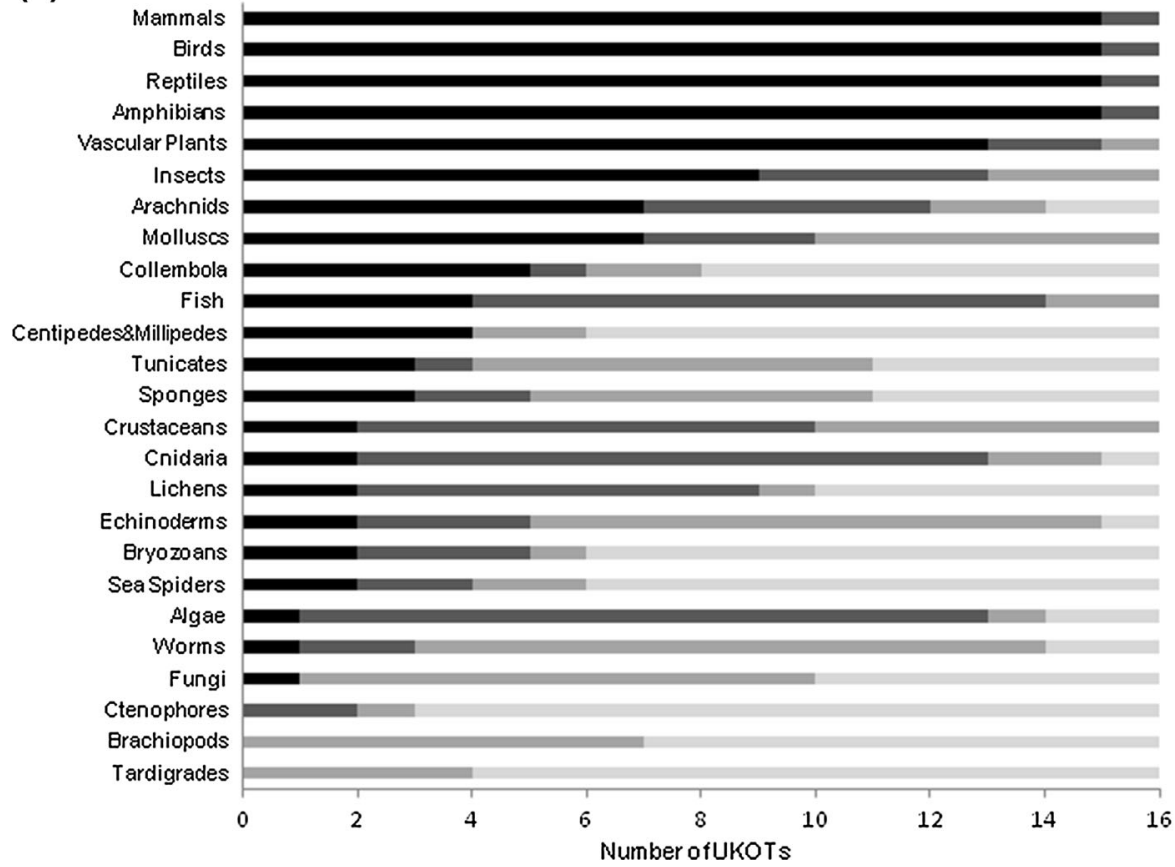

Fig. 3 UKOTs (a) and taxonomic groups (b) ranked for level of knowledge (4 = list compiled from authoritative literature, confident of complete or near complete coverage of taxonomic classes, input from experts received, $3=$ list compiled from authoritative literature, coverage of taxonomic classes reasonable but known to be incomplete, little or no input from experts, $2=$ preliminary list known to be incomplete, no input from experts, $1=$ no records found) across the UKOTs

UKOTs (Fig. 3). Caribbean UKOTs tended to have lower median knowledge scores than non-Caribbean island UKOTs, particularly compared to those in the Atlantic. As outlined above, the difference in knowledge levels between UKOTs was closely linked to the extent of research conducted on non-vertebrate groups, with generally good, and relatively consistent, knowledge only on the occurrence of the vertebrate species (Fig. 3). 


\section{Identifying gaps in knowledge in Global IUCN Red List assessments}

We found that Global Red List assessments have been made using IUCN criteria for 2606 species with records on the UKOTs (see Table 1 for a break down of assessments). Likelihood of assessment did not differ between endemics (145 species; $9 \%$ ) and nonendemics $(2461 ; 8 \%)$ but, not surprisingly, endemic species were much more likely to be listed as Globally Threatened (111 species; $75 \%$ of those assessed) than non-endemics $(291 ; 12 \%)\left(\chi^{2}=126.76, \mathrm{p} \leq 0.001\right)$.

Vertebrates occurring in the UKOTs were 16 times more likely to have been Red List assessed than non-vertebrates $\left(\chi^{2}=17.64, \mathrm{p}<0.001\right)$ (Fig. 2). Thus, while $1856(45 \%)$ native vertebrates have undergone assessment, only 758 (3\%) native non-vertebrates had been assessed, 286 (38\%) of which were vascular plants (Fig. 4). The proportion of species assessed within individual UKOTs was negatively correlated with the level of knowledge (median knowledge score) $\left(\mathrm{R}^{\mathrm{s}}=-0.83, \mathrm{p}<0.001\right)$, but not with the total number of native species known $\left(\mathrm{R}^{\mathrm{s}}=-0.376, \mathrm{p}=0.075\right)$. The proportion of endemics assessed however, was not correlated with knowledge $\left(\mathrm{R}^{\mathrm{s}}=-0.34, \mathrm{p}=0.196\right)$.

\section{Identifying true species richness}

We classified the estimates of species richness for 130 UKOT-taxonomic group combinations as complete or near-complete (score 4). Knowledge of bird and reptile occurrence was scored as 4 in all UKOTs; all UKOTs had at least three taxonomic groups with knowledge scores of 4 (i.e. included in the model) and, with the exception of tardigrades, brachiopods and ctenophores (excluded), and all taxonomic groups had a score of 4 in at least one UKOT (and all but three taxonomic groups had more complete scores). This enabled us to fit a model to these values, assuming that estimates of richness were complete, and derive estimates for most other taxonomic groups. Model fit was reasonable

Table 1 The native species assessed for the IUCN Red List

\begin{tabular}{|c|c|c|c|c|c|c|c|c|c|}
\hline Group & Assessed & $\mathrm{EX}^{\mathrm{a}}$ & EW & $\mathrm{CR}$ & $\mathrm{EN}$ & VU & NT & $\mathrm{LC}$ & DD \\
\hline Mammals & 109 & & & 1 & 5 & 5 & 2 & 69 & 27 \\
\hline Birds & $986(22)$ & & & $7(4)$ & $21(4)$ & $46(11)$ & $50(2)$ & $861(1)$ & 1 \\
\hline Reptiles & $77(10)$ & & & $11(5)$ & $11(2)$ & $8(2)$ & 3 & $44(1)$ & \\
\hline Amphibians & $19(1)$ & & & 1 & $1(1)$ & & 2 & 15 & \\
\hline Fish & $661(3)$ & & & $11(1)$ & 13 & 46 & 51 & $468(1)$ & $72(1)$ \\
\hline Insects & $55(2)$ & & & $2(1)$ & & & 1 & 49 & $3(1)$ \\
\hline Crustaceans & $56(23)$ & & & $22(21)$ & & 1 & & $24(1)$ & $9(1)$ \\
\hline Molluscs & $40(12)$ & $1(1)$ & & $4(4)$ & & $7(5)$ & $2(1)$ & $20(1)$ & 6 \\
\hline Worms & $3(3)$ & & & $1(1)$ & & $1(1)$ & & & $1(1)$ \\
\hline Cnidaria & $314(1)$ & & & 2 & $4(1)$ & 54 & 78 & 168 & 8 \\
\hline Vascular Plants & $286(68)$ & & $1(1)$ & $32(21)$ & 35 (19) & $50(7)$ & $2(1)$ & $152(14)$ & $14(5)$ \\
\hline Total & $2606(145)$ & $1(1)$ & $1(1)$ & $94(58)$ & $90(27)$ & $218(26)$ & $191(4)$ & 237 (19) & $141(9)$ \\
\hline
\end{tabular}

Endemic species are shown in ()

a EX represents Nesopupa turtoni, which has subsequently been rediscovered on St Helena 


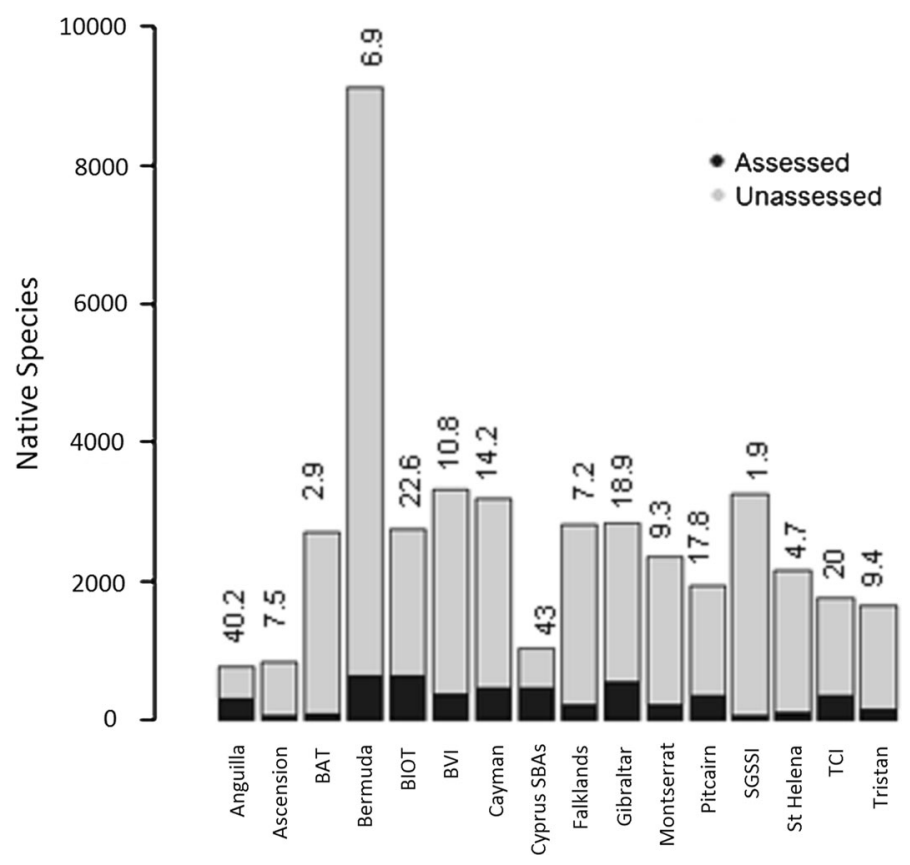

Fig. 4 Number of native species in the UKOTs showing number assessed (dark) and unassessed (grey) against IUCN Red List criteria. Numbers above bars give percentage of native species assessed

(Pearson's $\chi^{2}=4723, \mathrm{df}=100, \mathrm{p}<0.0001$ ) with both UKOT (Pearson's $\chi^{2}=134$, df $15, \mathrm{p}<0.0001$ ) and taxonomic group (Pearson's $\chi^{2}=608$, df $22, \mathrm{p}<0.0001$ ) having a significant effect. Parameter estimates are given in Table 2; unsurprisingly, parameter estimates for UKOTs were higher for tropical islands (i.e. Caribbean) and lower for isolated and higher latitude islands (e.g. in the south Atlantic), and varied across taxonomic groups as might be expected e.g. higher for biodiverse groups such as Crustaceans and low for Amphibians.

The sum of the UKOT-taxonomic group combinations was 134,600 which, accounting for species occurring in multiple territories, gave an estimate of 101,500 (95\% CLs $52,000-150,100$ ) native species predicted to occur in the UKOTs (Table 3) although given the error around this estimate it might best be reported as 'over 100,000'. A further 1000 species were recorded in the excluded taxonomic groups, but with poor or no coverage in many UKOTs this is will be an underestimate of true numbers. Individual UKOT estimates (Table 4) ranged from 2420 (for Ascension) to 18,820 (for Montserrat). As the sum of known native species was 32,100 , this suggests there are in the order of 70,000 species present yet to be recorded within the UKOTs, or that have not been documented in the data sources considered by this review.

The exercise was repeated for endemic species only (Tables 3, 4), producing an estimate of 3360 (95\% CLs 1000-5750) across the UKOTs suite. Further endemics are likely to occur in the taxonomic groups excluded from this analysis: brachiopods, tunicates, tardigrades, echinoderms, bryozoans, lower plants and 'other' groups. This suggests that there are in excess of 1800 species (possibly considerably more) endemic to a single 
Table 2 Parameter estimates for multi-level effects fitted to GLM to estimate true species richness

\begin{tabular}{|c|c|c|c|}
\hline UKOT & Parameter estimate & Taxonomic group $^{\mathrm{a}}$ & Parameter estimate \\
\hline Anguilla & 0.074 & Mammals & $-2.166^{* * *}$ \\
\hline Ascension & $-1.015^{* * *}$ & Birds & -0.024 \\
\hline BAT & $-1.031 * * *$ & Reptiles & $-2.628 * * *$ \\
\hline Bermuda & $0.278^{*}$ & Amphibians & $-5.457 * * *$ \\
\hline BIOT & -0.094 & Fish & $1.653 * * *$ \\
\hline BVI & 0.373 & Tunicates & -0.159 \\
\hline Cayman & $0.549 * * *$ & Insects & $1.518 * * *$ \\
\hline Cyprus SBA & $0.923 * * *$ & Collembola & $-1.757 * *$ \\
\hline Falklands & -0.314 & Arachnids & 0.090 \\
\hline Gibraltar & $0.891 * * *$ & Centipedes and millipedes & $-1.905^{* *}$ \\
\hline Montserrat & $1.036^{* * *}$ & Sea spiders & -1.108 \\
\hline Pitcairn & -0.266 & Crustaceans & $2.206^{* * * *}$ \\
\hline St Helena & -0.161 & Echinoderms & 0.219 \\
\hline SGSSI & $-0.700 * * *$ & Molluses & $1.366^{* * *}$ \\
\hline TCI & 0.334 & Worms & $1.531 * * *$ \\
\hline \multirow[t]{7}{*}{ Tristan } & $-0.883^{* *}$ & Cnidaria & $1.107 * * *$ \\
\hline & & Brozoans & 0.229 \\
\hline & & Sponges & -0.133 \\
\hline & & Vascular plants & $0.458^{*}$ \\
\hline & & Algae & 1.084 \\
\hline & & Lichens & $1.693 * * *$ \\
\hline & & Fungi & $0.635^{*}$ \\
\hline
\end{tabular}

Significance of parameters shown as $* \mathrm{p}<0.05, * *<0.01, * * *<0.001$

${ }^{\text {a }}$ Taxonomic groups are at varied taxonomic ranks following Costello (2001)

UKOT yet to be documented, or if they have been documented this was not discovered by our robust searches.

\section{What determines knowledge of biodiversity at the UKOT level?}

The uni-variate GLMs found only weak relationships between our explanatory variables and UKOT knowledge scores, with only ocean/sea showing a relationship significant at $\mathrm{p} \leq 0.05$ (greatest knowledge Antarctic $>$ Atlantic $>$ Pacific $>$ Indian $>$ Caribbean $>$ Mediterranean). The GLM for visitor numbers were run against a reduced number of UKOTs as we were only able to obtain estimates of visitor numbers for nine; this variable was excluded from the subsequent multi-variate analyses. As relationships with some variables may have been non-linear, we repeated uni-variate GLMs after log transformation for the distance variables, GDP and population variables, with no change in results. Incorporating more than two variables in multi-variate models did not improve performance; in Table 5 we present the best performing models, all of which contained ocean/sea plus one other explanatory variable. The most parsimonious model contained ocean/sea and GDP, although the performance was little better than for other models containing 
Table 3 Known and estimated totals of all native species, and species endemic to a single UKOT, across the UKOT suite by taxonomic group

\begin{tabular}{|c|c|c|c|c|}
\hline & $\begin{array}{l}\text { Estimated } \\
\text { species total }\end{array}$ & $\begin{array}{l}\text { Known } \\
\text { species total }\end{array}$ & $\begin{array}{l}\text { Estimated endemic } \\
\text { species total }\end{array}$ & $\begin{array}{l}\text { Known endemic } \\
\text { species total }\end{array}$ \\
\hline Mammals & 115 & 105 & 0 & 0 \\
\hline Birds & 966 & 966 & 22 & 22 \\
\hline Reptiles & 130 & 130 & 40 & 40 \\
\hline Amphibians & 12 & 12 & 1 & 1 \\
\hline Fish & 7908 & 2809 & 152 & 33 \\
\hline Tunicates & 1853 & 310 & - & 0 \\
\hline Insects & 10,078 & 7044 & 608 & 518 \\
\hline Collembola & 394 & 96 & 24 & 14 \\
\hline Arachnids & 2427 & 816 & 256 & 149 \\
\hline $\begin{array}{l}\text { Centipedes and } \\
\text { Millipedes }\end{array}$ & 345 & 65 & 11 & 5 \\
\hline Sea Spiders & 725 & 173 & 8 & 1 \\
\hline Tardigrades & - & 38 & - & 0 \\
\hline Crustaceans & 19,303 & 3244 & 882 & 153 \\
\hline Echinoderms & 2440 & 536 & - & 1 \\
\hline Molluscs & 7982 & 3454 & 178 & 123 \\
\hline Brachiopods & - & 30 & - & 0 \\
\hline Worms & 10,402 & 1526 & 505 & 53 \\
\hline Cnidaria & 5835 & 1310 & 60 & 9 \\
\hline Ctenophores & - & 10 & - & 0 \\
\hline Bryozoans & 2696 & 503 & - & 0 \\
\hline Sponges & 1897 & 446 & 126 & 18 \\
\hline Vascular plants & 3785 & 3544 & 221 & 188 \\
\hline Lower plants & - & - & - & 0 \\
\hline Algae & 9082 & 1711 & 22 & 11 \\
\hline Lichens & 3603 & 1089 & 99 & 58 \\
\hline Fungi & 8452 & 1144 & 280 & 26 \\
\hline Other & - & 1001 & - & 3 \\
\hline
\end{tabular}

It was not possible to produce estimates for tardigrades, brachiopods, ctenophores, lower plants or 'other' taxa

ocean/sea. This model gave a highly significantly better fit than the null model (likelihood ratio test, $\chi^{2}=31.0, \mathrm{df}=6, \mathrm{p} \leq 0.001$ ).

\section{Discussion}

This paper provides an extensive synthesis and collation of species records for all taxonomic groups for the UKOTS, and thus provides unparalleled baseline information on the biodiversity of this geographically disparate but politically linked group of Territories. It also estimates the true number of species which may exist within these Territories, albeit 
Table 4 Known and estimated totals of all native species, and species endemic to a single UKOT, by UKOT suite

\begin{tabular}{lcccc}
\hline & $\begin{array}{l}\text { Estimated species } \\
\text { total }\end{array}$ & $\begin{array}{l}\text { Known species } \\
\text { total }\end{array}$ & $\begin{array}{l}\text { Estimated endemic } \\
\text { species total }\end{array}$ & $\begin{array}{l}\text { Known endemic } \\
\text { species total }\end{array}$ \\
\hline Anguilla & 7193 & 761 & 44 & 5 \\
Ascension & 2418 & 827 & 89 & 48 \\
BAT & 2380 & 2701 & 0 & 1 \\
Bermuda & 8821 & 9128 & 321 & 321 \\
BIOT & 6076 & 2754 & 26 & 9 \\
BVI & 9697 & 3315 & 359 & 14 \\
Cayman & 11,566 & 3188 & 321 & 106 \\
CSBAs & 16,945 & 1030 & 0 & 0 \\
Falklands & 4876 & 2519 & 82 & 2 \\
Gibraltar & 16,279 & 2843 & 7 & 85 \\
Montserrat & 18,820 & 2339 & 99 & 99 \\
Pitcairn & 5117 & 1814 & 205 & 77 \\
SGSSI & 3316 & 3104 & 84 & 502 \\
St Helena & 5681 & 1885 & 1082 & 16 \\
TCI & 9326 & 1650 & 279 & 183 \\
Tristan & 2760 & 1646 & 373 & 2 \\
\hline
\end{tabular}

Estimated totals do not include Tardigrades, Brachiopods, Ctenophores, lower plants or 'other' taxa

Table 5 Best performing GLMs describing biodiversity knowledge within UKOTs, as described by the number of taxonomic groups with complete/near-complete knowledge

\begin{tabular}{llll}
\hline Model & Log likelihood & $\mathrm{AIC}_{\mathrm{c}}$ & $\Delta \mathrm{AIC}_{\mathrm{c}}$ \\
\hline Ocean, GDP & -33.35 & 102.70 & 0 \\
Ocean, specialist & -33.75 & 104.09 & 1.39 \\
Ocean, population & -34.32 & 105.22 & 2.52 \\
Ocean, higher learning & -34.34 & 105.26 & 2.56 \\
\hline
\end{tabular}

Italic values indicate the best performing model

within a wide range, and reliant upon a number of assumptions. Key within these are that the patterns of species richness across taxonomic groups are the same across all Territories as they are for those with good knowledge, such as Bermuda and SGSSI. Similarly, we assumed that patterns of species richness across Territories are the same for all taxonomic groups as they are for those groups, such as birds and reptiles, for which we have complete data. Both assumptions may be flawed; for example, migrant species with high dispersal capacities (e.g. birds and marine mammals) may be overrepresented in the taxonomic groups relied upon for our models.

Despite incomplete data and limited knowledge for many UKOTs and taxonomic groups, the high conservation value of the UKOTs is clear with over 32,000 native species recorded, of which over 1500 are endemic and an estimated 70,000 species (including a minimum estimate of 1800 endemics) yet to be documented. Small isolated islands, such 
as most of the UKOTs, often support high levels of endemism (Whittaker 1998; Heaney 2000), and their wide geographic distribution and habitat types will also result in high level of species richness for the island suite as a whole: as a consequence the contrast between species richness in the UKOTs and the UK mainland is considerable. The figures for the UKOTs dwarf the c.90 endemic species known to occur in mainland UK (unpublished data, Natural England). The island UKOTs cover approximately 17,635 km² (RSPB 2014) equivalent to ca $7.3 \%$ of the area of mainland UK $\left(241,930 \mathrm{~km}^{2}\right.$; World Bank 2015), but support over 16 times as many known (terrestrial) endemics. Furthermore, our estimate of a total of over 100,000 species (most yet to be discovered) across all UKOTs exceeds that of mainland UK, for which the total of approximately 70,000 species to have been documented to date (Natural History Museum 2015) is likely to be approaching the true total given the high level of biological recording in mainland UK.

Despite the high value of biodiversity on the UKOTs our knowledge of species presence, distribution and status is, with a few exceptions, relatively poor and highly variable between taxa and islands. In general, it is far better for vertebrates and vascular plants than for small bodied invertebrates and lower plants. This is a pattern common elsewhere including the mainland UK, for which good knowledge on status is available for $58 \%$ of vertebrates but just $4 \%$ of invertebrates (Burns et al. 2013) and has been attributed to factors such as differing ease of survey and monitoring and levels of interest in species groups.

Level of knowledge also varies between islands being, generally, lower in the Caribbean, (with the exception of Bermuda), than non Caribbean islands with these between island differences driven mainly by differences in knowledge of invertebrate taxa. Although our analysis did not identify strong relationships between knowledge and possible determinants other than geographic variation, a number of recognised factors might explain why some islands have received more attention than others including logistical constraints, such as ease of access due to geographic location (Hendriks and Duarte 2008; Jarić et al. 2015), as well as financial ones such as island wealth (e.g. Fisher et al. 2011). However, there appears to be a strong degree of chance-whether there is a resident scientist, or the island hosts a relevant research institute-which de Lima et al. (2011) identified and labelled 'serendipitous historical events and geopolitics'. Thus, the detailed knowledge of Bermudan biodiversity stems largely from the efforts of one dedicated individual; the comprehensive coverage of SGSSIs and BAT is a consequence of the work of the British Antarctic Survey field stations based there and the longstanding scientific interest in the Antarctic. We should recognise the enormous value provided to conservation of species and sites where such knowledge exists.

IUCN red lists provide a standardised and internationally recognised approach to assessing species status and threat, and the extent of Red List assessment can be recognised as valuable metric of knowledge of biodiversity at different scales. The nature and extent of red list assessments for the UKOTs reflects the overall knowledge of biodiversity; relatively poor, biased towards vertebrates and with a high degree of between-UKOT variation. Thus, only $9 \%$ of UKOT endemics have been assessed against Red List criteria, $25 \%$ of which are vertebrates; notably, Red Lists assessments have been made, and are updated regularly, for all bird species. Three-quarters of the UKOT endemic species that have been assessed are globally threatened (Online Resource 4), compared to only $12 \%$ of assessed non-endemic species and $30 \%$ of all species assessed globally (IUCN 2014). This high proportion of globally threatened endemics highlights the vulnerability of many species in the UKOTs. Although naturally small population and range sizes of many species may mean downgrading of Red List status will never be possible, the precarious 
nature of biodiversity in the UKOTs is exacerbated by the weaknesses in environmental legislation such as control of development and protection of important sites for biodiversity (FIELD and RSPB 2013).

\section{Future priorities}

In terms of increasing our knowledge of biodiversity (i.e. the presence, distribution and population size of species) on the UKOTs, the highest taxonomic priorities currently are invertebrates, non-vascular lower plants, lichen, fungi and marine biodiversity. This is particularly true for the islands of Anguilla, Montserrat, Cayman and British Virgin islands, for which our species lists were known to be incomplete for most taxonomic groups. All these islands fall within the Caribbean hotspot and could benefit from a wider regional effort.

The biodiversity data searches for the Cyprus SBAs found many resources for Cyprus at an island level, however little data was openly available specifically to the SBAs so our knowledge of the biodiversity of the Cyprus SBAs is the poorest of all the UKOTs (Fig. 3). This was a consequence of the biologically and geographically-artificial limits of the Cyprus SBAs, which will have little influence on biological science and recording within Cyprus as a whole. Improved knowledge of the species which occur in the SBAs will strengthen our understanding of how the UK can best support conservation efforts both within the UKOT but also more widely across Cyprus.

Knowing what species occur in the UKOTs is the first step in enabling robust conservation actions to prevent the loss of this biodiversity. A key need is to gain an understanding of the distributions and populations of poorly represented groups to inform conservation and development decisions such as the designation of protected areas and the impacts of development as well as to improve environmental protection frameworks.

The current lack of completed IUCN Red List assessments means that the status of $91 \%$ of endemic UKOT species is unknown and thus appropriate conservation action cannot be developed, let alone prioritised. It is also true that many of the species documented have been recorded only a very few times, or have not been recorded for many years-such as the endemic St Helena Darter Sympetrum dilatatum which was last recorded in 1963 (Suhling and Martens 2013). Such species may be extinct, or facing extinction, so assessing their current status should be regarded as an urgent priority.

The UKOTs currently suffer from the worrying combination of high endemism, high threat and low knowledge. Consequently, the UK Government must make the conservation of UKOT biodiversity a higher priority and provide adequate support to Territory governments to increase our knowledge of and prevent the loss of unique species.

Acknowledgments The authors would like to thank the time given in kind by the hundreds of people that provided data and commented on species lists. In particular the authors would like to acknowledge the input of the following organisations and individuals; Peter Carr, Alastair Lavery, Dr Peter Ryan, Prof Charles Sheppard, Dr Wolfgang Sterrer, Anguilla National Trust, Army Ornithological Society, Ascension Conservation Department, Birdlife Cyprus, BirdLife International, British Antarctic Survey, Chagos Conservation Trust, Coral Cay Conservation, Department for Environment Food and Rural Affairs, Department for the Environment Cayman Islands, Department of Environment Montserrat, Durrell Wildlife Conservation Trust, Environmental Management Division St Helena, Falklands Conservation, Gibraltar Botanical Gardens, Gibraltar Government, Gibraltar Ornithological and Natural History Society, Government of Bermuda, Government of Tristan da Cunha, Joint Nature Conservation Committee, Montserrat National Trust, National Trust of the Cayman Islands, Pitcairn Natural Resources Department, Royal Botanic GardensKew, South Georgia Heritage Trust, St Helena National Trust, Turks and Caicos National Trust. 
Funding This study was funded by the UK Foreign and Commonwealth Office.

\section{Compliance with ethical standards}

Disclosure of potential conflicts of interest The research was funded under an accountable grant agreement with the Foreign \& Commonwealth Office.

Conflicts of interest The authors declare that they have no conflicts of interest.

Open Access This article is distributed under the terms of the Creative Commons Attribution 4.0 International License (http://creativecommons.org/licenses/by/4.0/), which permits unrestricted use, distribution, and reproduction in any medium, provided you give appropriate credit to the original author(s) and the source, provide a link to the Creative Commons license, and indicate if changes were made.

\section{References}

Angel A, Cooper J (2006) A review of the impacts of introduced rodents on the island of Tristan da Cunha and Gough. Royal Society for the Protection of Birds, Sandy

Blanchet FG, Legendre P, Borchard D (2008) Forward selection of explanatory variables. Ecology $89: 2623-2632$

Brooks TM, Mittermeier RA, Mittermeier CG, da Fonseca GAB, Rylands AB, Konstant WR, Flick P, Pilgrim J, Oldfield S, Magin G, Hilton-Taylor C (2002) Habitat loss and extinction in the hotspots of biodiversity. Conserv Biol 16:909-923

Brooks TM, Mittermeier RA, da Fonseca GAB, Gerlach J, Hoffmann M, Lamoreux JF, Mittermeier CG, Pilgrim JD, Rodrigues ASL (2006) Global biodiversity conservation priorities. Science 313:58-61

Burnham KP, Anderson DR (2007) Model selection and multimodel inference: a practical informationtheoretic approach. Springer, New York

Burns F, Eaton MA, Gregory RD, Al Fulaij N, August TA, Biggs J, Bladwell S, Brereton T, Brooks D, Clubbe C, Dawson J, Dunn E, Edwards B, Falk S, Gent T, Gibbons D, Gurney M, Haysom K, Henshall S, Hodgetts N, Isaac NJB, McLaughlin M, Musgrove AJ, Noble D, O’Mahony E, Pacheco M, Roy DB, Sears J, Shardlow M, Stringer C, Taylor A, Thompson P, Walker K, Walton P, Willing MJ, Wilson J, Wynde R (2013) State of nature report. The state of nature partnership

Churchyard T, Eaton M, Hall J, Millet J, Farr A, Cuthbert R, Stringer C (2014) The UK's wildlife overseas: a stocktake of nature in our Overseas Territories. RSPB, Sandy

Cinotta PR, Wisnewski J, Engelman R (2000) Human population in the biodiversity hotspots. Nature 404:990-992

Clark JA, May RM (2002) Taxonomic bias in conservation research. Science 297:191-192

Costello MJ, Emblow C, White R (2001) European Register of Marine Species. A check-list of marine species in Europe and a bibliography of guides to their identification. Patrimoines Nat 50:1-463

Cuthbert RJ (2004) Breeding biology and population estimate of the Atlantic petrel, Pterodroma incerta, and other burrowing petrels at Gough Island, South Atlantic Ocean. Emu 104:221-228

Dawson J, Oppel S, Cuthbert R, Holmes N, Bird JP, Butchart SHM, Spatz DR, Tershy B (2015) Prioritizing islands for the eradication of invasive vertebrates in the United Kingdom Overseas Territories. Conserv Biol 29:143-153

De Broyer C, Koubbi P, Griffiths HJ, Raymond B, Udekem d'Acoz C d', Van de Putte AP, Danis B, David B, Grant S, Gutt J, Held C, Hosie G, Huettmann F, Post A, Ropert-Coudert Y (2014) Biogeographic Atlas of the Southern Ocean. Scientific Committee on Antarctic Research, Cambridge, pp 498

de Lima RF, Bird JP, Barlow J (2011) Research effort allocation and the conservation of restricted-range island bird species. Biol Conserv 144:627-632

Durand-Delga M, Villiaumey M (1963) Sur la stratigraphie et la tectonique du Jebel Moussa. B Soc Geol Fr 5:70-79

FIELD and RSPB (2013) An assessment of environmental protection frameworks in the UK Overseas Territories. http://www.rspb.org.uk/Images/EnvironmentalGovernanceReviewFeb2013_tcm9-342020. pdf

Fisher R, Radford BT, Knowlton N, Brainard RE, Michaelis FB, Caley MJ (2011) Global mismatch between research effort and conservation needs of tropical coral reefs. Conserv Lett 4:64-72 
Foreign Commonwealth Office (2012) The Overseas Territories: security, success and sustainability, CM 8374. www.gov.uk

Friedlander AM, Caselle JE, Ballesteros E, Brown EK, Turchik A, Sala E (2014) The real bounty: marine biodiversity in the Pitcairn Islands. PLoS ONE 9:e100142. doi:10.1371/journal.pone.0100142

Game ET, Kareiva P, Possingham HP (2013) Six common mistakes in conservation priority setting. Conserv Biol 27:480-485

Gaston KJ (1994) Rarity. Chapman and Hall, London

Havery S, Churchyard T, Eaton M, Hall J, Vickery J, Millet J, Cuthbert R, Stringer C (2015) The UK's wildlife overseas: a stocktake of nature in our land-based Overseas Territories. RSPB, Sandy

Heaney LR (2000) Dynamic disequilibrium: a long-term, large scale perspective on the equilibrium model of island biogeography. Global Ecol Biogeogr 9:59-74

Hendriks IE, Duarte CM (2008) Allocation of effort and imbalances in biodiversity research. J Exp Mar Biol Ecol 360:15-20

Hilton GM, Cuthbert RJ (2010) The catastrophic impact of invasive mammalian predators on birds of the UK Overseas Territories: a review and synthesis. Ibis 152:443-458

IUCN (2014) The IUCN Red List of threatened species. Version 2014.2. www.iucnredlist.org

Jarić I, Knežević-Jarić J, Gessner J (2015) Global effort allocation in marine mammal research indicates geographical, taxonomic and extinction risk-related biases. Mamm Rev 45:54-62

Kier G, Kreft H, Lee TM, Jetz W, Ibisch PL, Nowicki C, Mutke J, Bartholott W (2009) A global assessment of endemism and species richness across island and mainland regions. PNAS 106:9322-9327

Kingsford RT, Watson JEM, Lundquist CJ, Venter O, Hughes L, Johnston EL, Atherton J, Gawel M, Keith DA, Mackey BG, Morley C, Possingham HP, Raynor B, Recher HF, Wilson KA (2009) Major conservation policy issues for biodiversity in Oceania. Conserv Biol 23:834-840

Myers N, Mittermeier RA, Mittermeier CG, da Fonseca GAB, Kent J (2000) Biodiversity hotspots for conservation priorities. Nature 403:853-858

Natural history museum (2015) http://www.nhm.ac.uk/research-curation/scientific-resources/biodiversity/ uk-biodiversity/uk-species/index.html

Oldfield S, Sheppard C (1997) Conservation of biodiversity and research needs in the UK Dependent Territories. J App Ecol 34:1111-1121

Owen EF, Rose EPF (1997) Early Jurassic brachiopods from Gibraltar, and their tethyan affinities. Palaeontology 40:497-513

Prince PA, Croxall JP (1996) Birds of South Georgia. Bull Br Orn club 116:81-104

Procter D, Fleming LV (eds) (1999) Biodiversity: the UK Overseas Territories. Joint Nature Conservation Committee, Peterborough

Rodriguez-Sanchez F, Perez-Barrales R, Ojeda F, Vargas P, Arroyo J (2008) The strait of Gibraltar as a melting pot for plant diversity. Quater Sci Rev 27:2100-2117

RSPB (2014) Eradication of invasive alien vertebrates in the UK Overseas Territories: a prioritised framework for island restoration to enable the UK Overseas Territories' biodiversity strategy. RSPB, London, p 68

SAS Institute (2011) SAS for Windows 9.3

SBAA (2015) www.sbaadministration.org/index.php/background Accessed 29 July 2015

Segan DB, Bottrill MC, Baxter WJ, Possingham HP (2010) Using conservation evidence to guide management. Conserv Biol 25:200-202

Sheppard CRC, Bowen BW, Chen AC, Craig MT, Eble J, Fitzsimmons N, Gan C, Gaither MR, Gollock M, Keshavmurthy S, Koldewey H, Mortimer JA, Obura D, Pfeiffer M, Rogers AD, Sheppard ALS, Vogler C, Wörheide G, Yang MC, Yesson C (2013) British Indian Ocean Territory (the Chagos Archipelago): setting, connections and the marine protected area. In Sheppard CRC (ed) Coral reefs of the United Kingdom Overseas Territories. Coral Reefs of the World 4, Springer, Berlin

Suhling F, Martens A (2013) Sympetrum dilatatum. The IUCN Red List of Threatened Species. Version 2014.3. www.iucnredlist.org. Accessed 19 February 2015

Sutherland WJ, Pullin AS, Dolman PM, Knight TM (2004) The need for evidence-based conservation. Trends Ecol Evol 19:305-308

Tear TH, Stratton BN, Game ET, Brown MA, Apse CD, Shirer RR (2014) A return-on-investment framework to identify conservation priorities in Africa. Biol Cons 173:42-52. doi:10.1016/j.biocon. 2014.01.028

Teelucksingh S, Nunes PALD, Perrings C (2013) Biodiversity -based development in Small island developing states. Environ Dev Econ 18:381-391

Waldron A, Mooers AO, Miller DC, Nibbelink N, Redding D, Kuhn TS, Timmons Roberts J, Gittleman JL (2013) Targeting global conservation funding to limit immediate biodiversity declines. PNAS. doi:10. 1073/pnas.1221370110 
Weber SB, Weber N, Ellick J, Avery A, Frauenstein R, Godley BJ, Sim J, Williams N, Broderick AC (2014) Recovery of the South Atlantic's largest green turtle nesting population. Biodivers Conserv 23:3005-3018

Whittaker RJ (1998) Island biogeography: ecology, evolution, and conservation. Oxford University Press, Oxford

World Bank (2015) data.worldbank.org/indicator/AG.LND.TOTL.K2. Accessed 01 June 2015 